\title{
An effective simulation technique to evaluate loss of load expectation
}

\author{
Nahid-Al-Masood, Md. Khurram Monir Rabby, Mamun Rabbani, Mafruha Ahmed, Proteeti \\ Peya
}

Department of Electrical and Electronic Engineering, Bangladesh University of Engineering and Technology, Dhaka-1000, Bangladesh

Email address:

nahid@eee.buet.ac.bd (N. -Al-Masood),khurram.rabby@gmail.com (Md. K. Monir Rabby)

To cite this article:

Nahid-Al-Masood, Md. Khurram Monir Rabby, Mamun Rabbani, Mafruha Ahmed, Proteeti Peya. An Effective Simulation Technique to Evaluate Loss of Load Expectation. Journal Electrical and Electronic Engineering. Vol. 1, No. 1, 2013, pp. 29-34.

doi: 10.11648/j.jeee.20130101.13

\begin{abstract}
Risk index of loss-of-load expectation is traditionally used to determine generation adequacy. However, because responsibility of generation installation and demand increases with different entities, both generation and load need to be examined to evaluate the resource adequacy of today's deregulated power systems. An electric utility's main concern is to plan, design, operate and maintain its power supply to provide an acceptable level of reliability to its users. This clearly requires that standards of reliability be specified and used in all three sectors of the power system, i.e., generation, transmission and distribution. Reliability indices have been defined for the three sectors separately as well as for the bulk power system. Reliability criteria may be determined at the selected load points in the system for different combination of generators and transmission line failures. This paper presents an effective simulation method for the reliability assessment of reliability index, loss-of-load expectation (LOLE). This method is applied to Bangladesh Power System (BPS). BPS has a total installed capacity of around $6550 \mathrm{MW}$. The maximum demand of BPS is about $5700 \mathrm{MW}$. The relevant data of the generators and hourly load profiles are collected from the National Load Dispatch Center (NLDC) of Bangladesh and reliability index 'LOLE' is assessed for the last six years.
\end{abstract}

Keywords: Installed Capacity, Recursive Method, Forced Outage Rate (FOR), Bangladesh Power System (BPS), Probability Density Function (PDF), LOLE

\section{Introduction}

The optimal design of composite power system expansion planning is an important part of the overall planning task of electric power system under competitive electricity market environments. One of main keys of the successful generators and grid expansion planning comes from optimal reliability level/criteria decision. A methodology of taking the decision of the optimal reliability criteria (LOLE) for an optimal composite power system expansion planning is used considering generation and transmission systems simultaneously [1]. Hence, risk-based planning and market decision makings have to address both generation and transmission jointly. A procedure is used to combine both dynamic optimization and Monte Carlo simulation to generate a vector space of solution, from which optimal solutions for different objectives can then be easily obtained. Determining locational capacity and transmission requirements serves the example of such an application [2]. Inte- gration of large quantities of wind generation into existing power systems is a topic of concern and much study throughout the world. LOLE is used as a comparing parameter for this analysis [3]. Four representative populationbased intelligent search (PIS) procedures including genetic algorithm (GA), particle swarm optimization (PSO), artificial immune system (AIS), and ant colony system (ACS) are adopted to search the meaningful system states through their inherent convergence mechanisms. These probable failure states contribute most significantly to the adequacy indices including loss of load expectation (LOLE) [4]. A conventional reliability analysis is used to evaluate the capacity value of new generation based up location and forced outage rates. Adaptation of those methods has been used to show the capacity value of additional wind generation. However, it would also be helpful to have an easier, faster methodology to estimate the capacity value of wind generation. Analytical results from both a detailed reliability analysis e.g. LOLE technique are presented [5]. Monte Carlo simulation (MCS) and analytical technique are used 
in the development and utilization of wind-based distributed generation (DG) work with a new implementation of the islanding mode of operation in the assessment. The results are used to make the comparison the outcomes of the two proposed techniques; however, MCS requires much longer computational time. Moreover, the effect of islanding appears in the improvement of the loss of load expectation (LOLE) and loss of energy expectation (LOEE) [6]. In paper [7], Southwest Power Pool's (SPP) experience in analyzing generation adequacy is presented and this analysis is conducted by examining a common reliability index, Loss of Load Expectation (LOLE). According to North American Electric Reliability Corporation (NERC), smart grid reliability is defined by resource adequacy and operational security and such level of reliability is often measured by the Loss of Load Expectation (LOLE) with the typical criterion of 1 day in 10 years [8]. The optimum calculation of battery size when used as energy storage in standalone systems with renewable energy resources focus in this analysis is on the effect of battery charging/discharging characteristics on system reliability and cost. The Loss of Load Expectation (LOLE) index to evaluate the reliability of a standalone system consisting of wind turbines and battery storage system by taking the charging efficiency and discharge rate into consideration, the resulted LOLE is lower than what is expected [9]. In [10], the loss-of-load-expectation (LOLE) is considered as a good working group for the bulk power system operation and analysis. The reliability impacts of various levels of wind power penetration are investigated and compared with conventional power generation units. In this analysis, the percentage of penetration level is used to consider the corresponding LOLE situation LOLE [11]. An intermittent generation adequacy assessment including wind energy conversion systems (WECS) at multiple locations is described in [12]. In this analysis effective load-carrying capabilities (ELCC) obtained using the loss of load expectation (LOLE) and the loss of load frequency (LOLF) for a power system containing WECS are illustrated and compared. In the stochastic unit commitment, loss-of-loadexpectation (LOLE) is included as a constraint for calculating the cost of supplying the reserve [13]. In the analyses of ISO New England that has developed several means of presenting information that summarizes the need for future system development by market participants, loss of load expectation (LOLE), operable capacity, fuel diversity, environmental emissions, and congestion projections have been included [14]. As a basis of CBM calculation LOLE is analyzed in $[15,16]$. Aging characteristics of system components may impact the calculation of commonly used reliability indices such as loss of load expectation (LOLE) are described in [17]. The effect of islanding appears as an improvement of the loss of load expectation (LOLE) and loss of energy expectation (LOEE) [18]. A new method has been proposed in [19] to determine the capacity credit for renewable resource in the framework of resource adequacy. For this reason, optimization model is developed first to calculate the minimum resource procurement based on the system LOLE (Loss of Load Expectation) criterion [19]. According to the load growth of various types of customers, the loss of load expectation (LOLE) of the study distribution system is analyzed by the integration of probabilistic PV power generation model and the risk model of main transformer outage [20].

Reliability index 'LOLE' is assessed for the crisis of electrical demand in Bangladesh which is increasing rapidly due to population and industrial growth. LOLE gives the probable idea of any loss of load occurring in Bangladesh power system due to the scarcity of available generation. In this paper LOLE of BPS is evaluated for last six years to determine the reliability of the system.

\section{Generator and Load Model of BPS}

\subsection{Generator Model}

Simply, a generating unit for continuous operation is a Run-Fail-Repair-Run cycle that states that every generator has two states. They are- i) Unit availability and ii) Unit unavailability or forced outage rate (FOR). The unit availability means the long term probability that the generating unit will reside in on state and unit unavailability or FOR means the long term probability that the generating unit will reside in off state.

Mathematically FOR can be defined as,

$$
q=\frac{m}{m+r}
$$

Where,

$\mathrm{q}=\mathrm{FOR}$

$r=$ average run time of the generator

$m=$ average down time of the generator

Unit availability of a generating unit (p) can be defined as,

$$
p=\frac{r}{m+r}
$$

For a generating unit with capacity $=\mathrm{C}$ MW and FOR $=$ $\mathrm{q}$ and unit availability $=\mathrm{p}$, the probability density function (PDF) of forced outage capacity is shown in Figure 1.

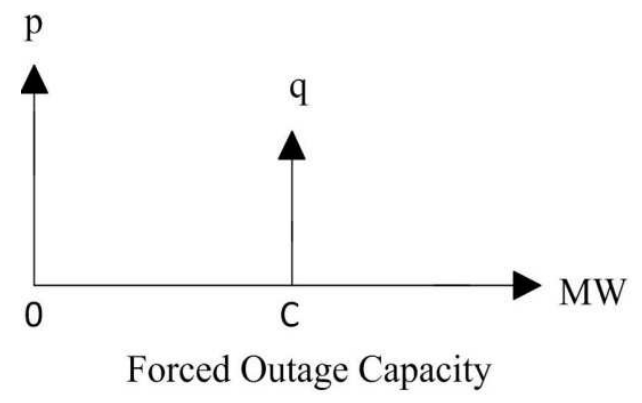

Figure 1. PDF of forced outage capacity of a generating unit 
BPS has a total installed capacity of around $6550 \mathrm{MW}$. The individual capacity and FOR of the generators are shown in Table 1.

Table 1. capacity and for of the generators of BPS

\begin{tabular}{|c|c|c|c|c|c|}
\hline Gen No & $\begin{array}{l}\text { Capacity } \\
\text { (MW) }\end{array}$ & FOR & Gen No & $\begin{array}{l}\text { Capacity } \\
\text { (MW) }\end{array}$ & FOR \\
\hline 1 & 210 & 0.16 & 34 & 120 & 0.04 \\
\hline 2 & 50 & 0.113 & 35 & 77 & 0.101 \\
\hline 3 & 109 & 0.07 & 36 & 100 & 0.04 \\
\hline 4 & 55 & 0.185 & 37 & 125 & 0.1 \\
\hline 5 & 55 & 0.185 & 38 & 125 & 0.1 \\
\hline 6 & 210 & 0.095 & 39 & 110 & 0.301 \\
\hline 7 & 210 & 0.019 & 40 & 60 & 0.402 \\
\hline 8 & 210 & 0.08 & 41 & 28 & 0.5 \\
\hline 9 & 210 & 0.08 & 42 & 28 & 0.5 \\
\hline 10 & 64 & 0.116 & 43 & 20 & 0.045 \\
\hline 11 & 64 & 0.116 & 44 & 20 & 0.2 \\
\hline 12 & 150 & 0.013 & 45 & 20 & 0.2 \\
\hline 13 & 150 & 0.014 & 46 & 20 & 0.119 \\
\hline 14 & 150 & 0.014 & 47 & 60 & 0.5 \\
\hline 15 & 56 & 0.321 & 48 & 8 & 0.3 \\
\hline 16 & 56 & 0.321 & 49 & 450 & 0.07 \\
\hline 17 & 30 & 0.15 & 50 & 235 & 0.07 \\
\hline 18 & 100 & 0.3 & 51 & 125 & 0.07 \\
\hline 19 & 210 & 0.197 & 52 & 142 & 0.07 \\
\hline 20 & 210 & 0.197 & 53 & 45 & 0.07 \\
\hline 21 & 60 & 0.117 & 54 & 45 & 0.07 \\
\hline 22 & 28 & 0.6 & 55 & 110 & 0.11 \\
\hline 23 & 28 & 0.6 & 56 & 110 & 0.07 \\
\hline 24 & 12 & 0.15 & 57 & 50 & 0.1 \\
\hline 25 & 12 & 0.15 & 58 & 50 & 0.1 \\
\hline 26 & 12 & 0.15 & 59 & 50 & 0.1 \\
\hline 27 & 15 & 0.15 & 60 & 50 & 0.1 \\
\hline 28 & 15 & 0.15 & 61 & 50 & 0.1 \\
\hline 29 & 15 & 0.15 & 62 & 50 & 0.1 \\
\hline 30 & 15 & 0.15 & 63 & 50 & 0.1 \\
\hline 31 & 35 & 0.1 & 64 & 50 & 0.1 \\
\hline 32 & 35 & 0.1 & 65 & 50 & 0.1 \\
\hline 33 & 21 & 0.122 & 66 & 50 & 0.1 \\
\hline 67 & 50 & 0.1 & 77 & 50 & 0.1 \\
\hline 68 & 50 & 0.1 & 78 & 50 & 0.1 \\
\hline 69 & 50 & 0.1 & 79 & 50 & 0.1 \\
\hline 70 & 50 & 0.1 & 80 & 50 & 0.1 \\
\hline 71 & 50 & 0.1 & 81 & 50 & 0.1 \\
\hline 72 & 50 & 0.1 & 82 & 50 & 0.1 \\
\hline 73 & 50 & 0.1 & 83 & 50 & 0.1 \\
\hline 74 & 50 & 0.1 & 84 & 50 & 0.1 \\
\hline 75 & 50 & 0.1 & 85 & 50 & 0.1 \\
\hline 76 & 50 & 0.1 & 86 & 50 & 0.1 \\
\hline
\end{tabular}

2.2. Load Model and Load Duration Curve (LDC)
In order to calculate the load model of BPS, daily peak loads are collected from National Load Dispatch Center (NLDC) of Bangladesh. The occurrence probability of a specific load is then calculated for a specific year. The probability of occurrence of a specific load is calculated as,

$$
P_{g}=\frac{N_{g}}{N_{t}}
$$

Where,

$P_{g}=$ Probability of occurrence of a load

$N_{g}=$ No. of occurring days of that load in the observation period of 1 year

$N_{t}=$ Total no. of days in the observation period

Figure 2 shows the load vs. \% time plot of BPS of year 2012.

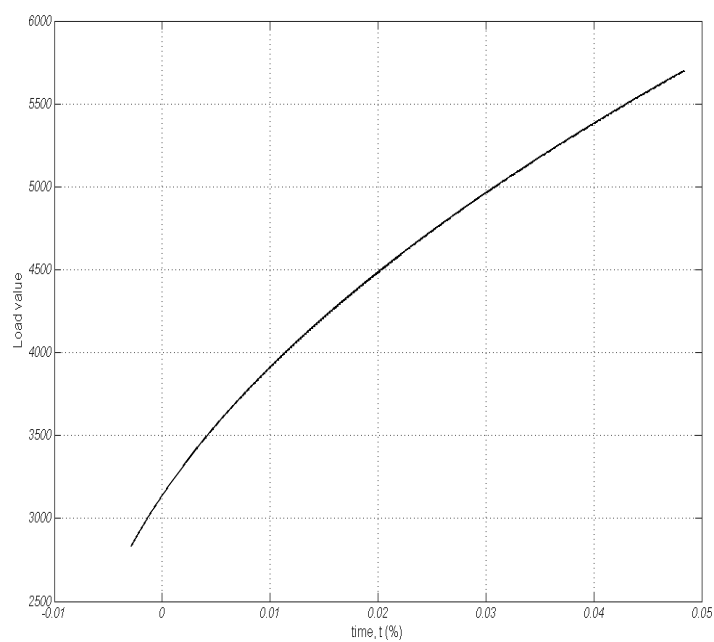

Figure 2. Load vs. \% time curve of BPS

\section{Analysis Technique}

\subsection{Capacity Outage Probability Table (COPT)}

The COPT is a table contains all the capacity states in an ascending order of outages magnitude. Each outage (capacity state) is multiplied by its probability. If the system contains identical units, Binomial distribution can be used. If the units are not identical, the procedure deals with all the states.

\subsubsection{Recursive Algorithm}

In case of large system, more practical approach is recursive technique which is described in what follows

The recursive expression for a state of X MW on forced outage after the addition of a generating unit of capacity $\mathrm{C}$ MW with forced outage rate $U$ is given by,

$$
p(X)=p^{\prime}(X)(1-u)+p^{\prime}(X-C) u
$$

Where, $\mathrm{p}(\mathrm{X})=$ the individual state probability. If $\mathrm{X}$ is less than $\mathrm{C}$, 


$$
p^{\prime}(X-C)=0
$$

Consider a power system with three generators of capacity $\mathrm{C}_{1}, \mathrm{C}_{2}$ and $\mathrm{C}_{3}$. Unit's availability is $\mathrm{a}_{1}, \mathrm{a}_{2}$ and $\mathrm{a}_{3}$, respectively and FOR is $\mathrm{u}_{1}, \mathrm{u}_{2}$ and $\mathrm{u}_{3}$, respectively. The steps of recursive algorithm for this small system are presented below in tabular format.

Table $21^{\text {st }}$ unit is added

\begin{tabular}{lllcc}
\hline State No & $\begin{array}{l}\text { Capacity } \\
\text { on outage }\end{array}$ & $\boldsymbol{p}^{\prime}(\boldsymbol{X})(\mathbf{1}-\boldsymbol{u})$ & $\boldsymbol{p}^{\prime}(\boldsymbol{X}-\boldsymbol{C}) \boldsymbol{u}$ & $\boldsymbol{p}(\boldsymbol{X})$ \\
\hline 1 & 0 & $1 \times\left(1-u_{1}\right)$ & $0 \times\left(u_{1}\right)$ & $p_{1}$ \\
2 & $\mathrm{C}_{1}$ & $0 \times\left(1-u_{1}\right)$ & $1 \times\left(u_{1}\right)$ & $p_{2}$ \\
\hline
\end{tabular}

Table $32^{\text {nd }}$ unit is added

\begin{tabular}{lllll}
\hline State No & $\begin{array}{l}\text { Capacity } \\
\text { on outage }\end{array}$ & $\boldsymbol{p}^{\prime}(\boldsymbol{X})(\mathbf{1}-\boldsymbol{u})$ & $\boldsymbol{p}^{\prime}(\boldsymbol{X}-\boldsymbol{C}) \boldsymbol{u}$ & $\boldsymbol{p}(\boldsymbol{X})$ \\
\hline 1 & 0 & $p_{1} \times\left(1-u_{2}\right)$ & $0 \times\left(u_{2}\right)$ & $p_{1}$ \\
2 & $\mathrm{C}_{1}$ & $p_{2} \times\left(1-u_{2}\right)$ & $0 \times\left(u_{2}\right)$ & $p_{2}$ \\
3 & $\mathrm{C}_{2}$ & $0 \times\left(1-u_{2}\right)$ & $p_{1} \times\left(u_{2}\right)$ & $p_{3}$ \\
4 & $\mathrm{C}_{1}+\mathrm{C}_{2}$ & $0 \times\left(1-u_{2}\right)$ & $p_{2} \times\left(u_{2}\right)$ & $p_{4}$ \\
\hline
\end{tabular}

Table $43^{\text {rd }}$ unit is added

\begin{tabular}{lllll}
\hline State No & Capacity on outage & $\boldsymbol{p}^{\prime}(\boldsymbol{X})(\mathbf{1}-\boldsymbol{u})$ & $\boldsymbol{p}^{\prime}(\boldsymbol{X}-\boldsymbol{C}) \boldsymbol{u}$ & $\boldsymbol{p}(\boldsymbol{X})$ \\
\hline 1 & 0 & $p_{1} \times\left(1-u_{3}\right)$ & $0 \times\left(u_{3}\right)$ & $p_{1}$ \\
2 & $\mathrm{C}_{1} \times\left(1-u_{3}\right)$ & $0 \times\left(u_{3}\right)$ & $p_{2}$ \\
3 & $\mathrm{C}_{2}$ & $p_{3} \times\left(1-u_{3}\right)$ & $p_{1} \times\left(u_{3}\right)$ & $p_{3}$ \\
4 & $\mathrm{C}_{1}+\mathrm{C}_{2}$ & $p_{4} \times\left(1-u_{3}\right)$ & $p_{2} \times\left(u_{3}\right)$ & $p_{4}$ \\
5 & $\mathrm{C}_{3}$ & $0 \times\left(1-u_{3}\right)$ & $p_{1} \times\left(u_{3}\right)$ & $p_{5}$ \\
6 & $\mathrm{C}_{1}+\mathrm{C}_{3}$ & $0 \times\left(1-u_{3}\right)$ & $p_{2} \times\left(u_{3}\right)$ & $p_{6}$ \\
7 & $\mathrm{C}_{2}+\mathrm{C}_{3}$ & $0 \times\left(1-u_{3}\right)$ & $p_{3} \times\left(u_{3}\right)$ & $p_{7}$ \\
8 & $\mathrm{C}_{1}+\mathrm{C}_{2}+\mathrm{C}_{3}$ & $0 \times\left(1-u_{3}\right)$ & $p_{4} \times\left(u_{3}\right)$ & $p_{8}$ \\
\hline
\end{tabular}

This is apparent from above calculation that for $\mathrm{n} \mathrm{ma-}$ chine there will be $2 \mathrm{n}$ states to calculate. But in practical case it is improbable to find $2 n$ number different states. If any two or more states have similar values their probability will be added under same state. As for an example, in table 4 , if $\mathrm{C} 1=\mathrm{C} 2$ then state 2 and 3, 6 and 7 will be equal. In that case at state 2 value of probability is similar to at state 3. Similarly at state 6 , probability is similar to at state 7 . Thus there is no need to have state 3 and 7 for further consideration. Numbers of states are reduced to 6 . This method is applied in every step of unit addition. As a result total numbers of states reduce by a considerable number.

After considering all the states, they are sorted in ascending order and cumulative probabilities are calculated. A sample calculation is shown in Table 5.
Table 5. sample calculation of cumulative probability

\begin{tabular}{|c|c|c|c|}
\hline State No & Capacity on outage & $p(X)$ & Cumulative probability \\
\hline 1 & 0 & $p_{1}$ & $\begin{array}{l}\mathrm{p}_{8}+\mathrm{p}_{7}+\mathrm{p}_{6}+\mathrm{p}_{5}+\mathrm{p}_{4}+ \\
\mathrm{p}_{3}+\mathrm{p}_{2}+\mathrm{p}_{1}=1\end{array}$ \\
\hline 2 & $\mathrm{C}_{1}$ & $p_{2}$ & $\mathrm{p}_{8}+\mathrm{p}_{7}+\mathrm{p}_{6}+\mathrm{p}_{5}+\mathrm{p}_{4}+\mathrm{p}_{3}+\mathrm{p}_{2}$ \\
\hline 3 & $\mathrm{C}_{2}$ & $p_{3}$ & $\mathrm{p}_{8}+\mathrm{p}_{7}+\mathrm{p}_{6}+\mathrm{p}_{5}+\mathrm{p}_{4}+\mathrm{p}_{3}$ \\
\hline 4 & $\mathrm{C}_{1}+\mathrm{C}_{2}$ & $p_{4}$ & $\mathrm{p}_{8}+\mathrm{p}_{7}+\mathrm{p}_{6}+\mathrm{p}_{5}+\mathrm{p}_{4}$ \\
\hline 5 & $\mathrm{C}_{3}$ & $p_{5}$ & $\mathrm{p}_{8}+\mathrm{p}_{7}+\mathrm{p}_{6}+\mathrm{p}_{5}$ \\
\hline 6 & $\mathrm{C}_{1}+\mathrm{C}_{3}$ & $p_{6}$ & $\mathrm{p}_{8}+\mathrm{p}_{7}+\mathrm{p}_{6}$ \\
\hline 7 & $\mathrm{C}_{2}+\mathrm{C}_{3}$ & $p_{7}$ & $\mathrm{P}_{8}+\mathrm{p}_{7}$ \\
\hline 8 & $\mathrm{C}_{1}+\mathrm{C}_{2}+\mathrm{C}_{3}$ & $p_{8}$ & $\mathrm{p}_{8}$ \\
\hline
\end{tabular}

\subsection{Loss of Load Expectation (LOLE)}

The LOLE risk expectation index is the most widely accepted and used probabilistic method in system reliability evaluation for generating systems. Two models are required and employed. One is the previously studied Load Duration Curve (LDC), and the other is the COPT. These two models are convolved (combined) in the process. The units of the LOLE are in days per year $(\mathrm{d} / \mathrm{y})$.

LOLE can be calculated as,

$$
L O L E=\sum t_{k} p_{k}\left(\frac{d}{y}\right)\left(L_{\max }>\text { Capacity }\right)
$$

Where, $p_{k}$ is the probability of kth capacity-in, $t_{k}$ is the duration that load demand exceeds the kth capacity-in and $\mathrm{n}$ is the number of state of capacity-in.

A sample calculation is shown in Table 6

\begin{tabular}{|c|c|c|c|}
\hline $\begin{array}{l}\text { Cap on out } \\
\text { (1) }\end{array}$ & $\begin{array}{l}\text { Probability } \\
\text { (2) }\end{array}$ & $\begin{array}{l}\text { Time, } t_{i}(\%) \\
(3)\end{array}$ & $\begin{array}{l}\text { Loss of load expected } \\
(2 \times 3)\end{array}$ \\
\hline 0 & $p_{1}$ & 0 & 0 \\
\hline $\mathrm{C}_{1}$ & $p_{2}$ & 0 & 0 \\
\hline $\mathrm{C}_{2}$ & $p_{3}$ & $t_{3}$ & $p_{3} \times t_{3}$ \\
\hline \multirow[t]{2}{*}{$\mathrm{C}_{\mathrm{n}}$} & $p_{n}$ & $t_{n}$ & $p_{n} \times t_{n}$ \\
\hline & $=1.0000$ & & $=\sum \square \square$ \\
\hline
\end{tabular}

Table 6. sample calculation of lole

Here, in the first two states, load is less than the available capacity so loss of load expectation is zero. But for the remaining cases, load value is above the available capacity 
so loss of load expectation is found.

If $100 \%$ of time represents 365 days, the LOLE will be,

$$
L O L E=\left(\sum p t\right) \times \frac{365}{100}(d / y)
$$

\section{Results}

BPS has a total installed capacity of around $6550 \mathrm{MW}$. Using the analysis technique presented in this paper, LOLE of BPS is evaluated from year 2007 to 2012. Table 7 presents the results.

\section{Table 7. LOLE of BPS}

\begin{tabular}{ll}
\hline Year & LOLE $(\mathbf{d} / \mathbf{y})$ \\
\hline 2012 & 5.7295 \\
2011 & 5.6395 \\
2010 & 5.6438 \\
2009 & 5.3963 \\
2008 & 5.4738 \\
2007 & 5.3693 \\
\hline
\end{tabular}

Graphically the results are shown in Figure 3.

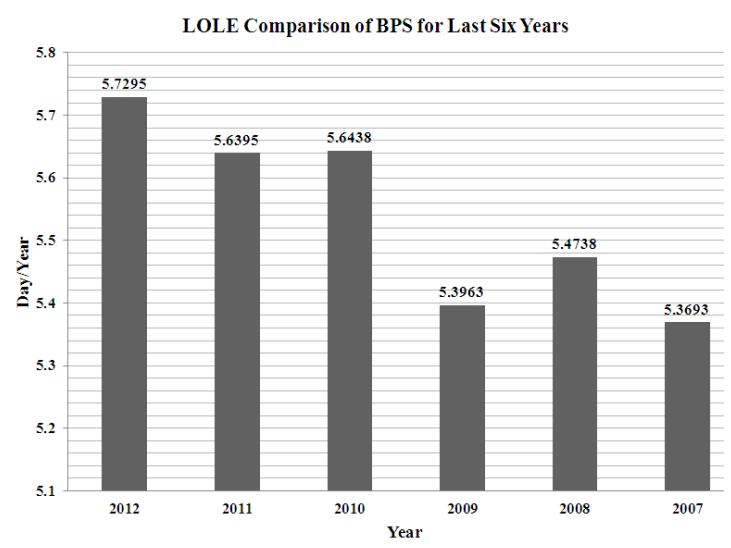

Figure 3. LOLE of BPSS

Reliability of a system is good if LOLE is low. With the increasing of demand, if the generation of the system is not increased then LOLE will be further increased which indicate the overall system instability. From Figure 2, in 2007 LOLP was $5.3693(\mathrm{~d} / \mathrm{y})$ which is considerably high. The following year in 2008 LOLE increased as demand increased but capacity remains almost same. In the very next year new generators were added and total capacity increased. Thus LOLE decreased to 5.3963 (d/y) in 2009. This capacity was same for next year so that LOLE increased with on-going power demand. With that amount of generation, LOLE didn't fall significantly because demand increased extensively due to the development in rural areas, industries and communication sector. In 2011 total capacity increased with the increasing generators. So LOLE improved comparatively. But in 2012, due to the development of industrialization and also the extension of urbanization, the demand of electrical energy has been increased significantly with respect to the increase in generators. As a result, the value of LOLE increased significantly.

\section{Conclusions}

Application of the reliability analysis techniques that have been widely used and accepted by the power industry allows for meaningful calculation of the effective capacity of variable generation resources. The impact of probabilistic power generation and the corresponding peak demands by power systems to the capacity expansion planning of main transformers is to meet the service reliability. A probabilistic reliability criterion, LOLE is used in this study. The system LOLE over the study years is determined by considering the growth rate of area peak loading and the available generation capacity. The procedure is used to compare the relative contributions and tradeoffs between transmission and generation to achieve a certain system risk for a particular period of time. The risk index delineates outages from transmission and generation inadequacy. The simulation results show a considerably high LOLE $(5.7295 \mathrm{~d} / \mathrm{y}$ in 2012) that indicates the poor reliability of the power system of Bangladesh. Lower reliability level causes the probability of loss continuity of the power system. To overcome this situation, system maintenance need to be high and loss of distribution need to be minimized. Additional generator association with the defaulted system can improve the overall system reliability. For the future further work, these reliability modeling and analysis tools can eventually be used to propose a new methodology of assessing the capacity credit of renewable generators and possibly the capacity credit of other intermittent energy sources.

\section{References}

[1] Jaeseok Choi; Thomas, R.; Zhifang Wang; El-Keib, A.; Billinton, R.; , "A study on probabilistic optimal reliability criterion determination in composite power system expansion planning," Power Engineering Society General Meeting, 2005. IEEE , vol., no., pp. 1277- 1284 Vol. 2, 12-16 June 2005

[2] Rau, N.S.; Fei Zeng; , "Dynamic optimizations of Monte Carlo simulation to assess locational capacity, transmission, and market parameters," Power Systems, IEEE Transactions on , vol.21, no.1, pp. 34- 42, Feb. 2006

[3] Scott Brown; William K. Marshall;, "Maritimes Area Wind Integration Study," Electrical and Computer Engineering, 2006. CCECE '06. Canadian Conference on , vol., no., pp.670-675, May 2006

[4] Lingfeng Wang; Singh, C.; , "Population-Based Intelligent Search in Reliability Evaluation of Generation Systems With Wind Power Penetration," Power Systems, IEEE Transactions on, vol.23, no.3, pp.1336-1345, Aug. 2008 
[5] Miller, N.W.; Jordan, G.A.; , "Evaluating wind capacity value in New York and California," Power and Energy Society General Meeting - Conversion and Delivery of Electrical Energy in the 21st Century, 2008 IEEE , vol., no., pp.1-7, 20-24 July 2008

[6] Atwa, Y.M.; El-Saadany, E.F.; Guise, A.-C.; , "Supply Adequacy Assessment of Distribution System Including WindBased DG During Different Modes of Operation," Power Systems, IEEE Transactions on , vol.25, no.1, pp.78-86, Feb. 2010

[7] Al-Alawi, Ameer; Nagle, Makarand; Zhu, Jinxiang; , "Utilizing reliability indices to study generation adequacy," Transmission and Distribution Conference and Exposition, 2010 IEEE PES , vol., no., pp.1-5, 19-22 April 2010

[8] Litvinov, E.; "What is reliable smart grid?" Power and Energy Society General Meeting, 2011 IEEE , vol., no., pp.1-2, 24-29 July 2011

[9] Delavaripour, H.; Karshenas, H.R.; Bakhshai, A.; Jain, P.; , "Optimum battery size selection in standalone renewable energy systems," Telecommunications Energy Conference (INTELEC), 2011 IEEE 33rd International, vol., no., pp.17, 9-13 Oct. 2011

[10] Ford, Andrew P.; Heath, Brandon; , "LOLE best practices working group," Power and Energy Society General Meeting, 2012 IEEE, vol., no., pp.1-5, 22-26 July 2012

[11] D'Annunzio, C.; Santoso, S.; , "Wind power generation reliability analysis and modeling," Power Engineering Society General Meeting, 2005. IEEE, vol., no., pp.35-39 Vol. 1,2005

[12] Wangdee, W.; Billinton, R.; , "Considering load-carrying capability and wind speed correlation of WECS in generation adequacy assessment," Energy Conversion, IEEE Transactions on , vol.21, no.3, pp.734-741, Sept. 2006

[13] Lei Wu; Shahidehpour, M.; Tao Li; , "Cost of Reliability Analysis Based on Stochastic Unit Commitment," Power
Systems, IEEE Transactions on , vol.23, no.3, pp.1364-1374, Aug. 2008

[14] Henderson, M.; Wong, P.; Platts, J.; Burke, R.; , "Planning for reliability, economics, and the environment in a deregulated market," Power and Energy Society General Meeting Conversion and Delivery of Electrical Energy in the 21st Century, 2008 IEEE, vol., no., pp.1-9, 20-24 July 2008

[15] M. M. Othman, A. Mohamed, and A. Hussain, "Available transfer capability assessment using evolutionary programming based capacity benefit margin,” Int. J. Elect. Power Energy Syst., vol. 28, no. 3, pp. 166-176, Mar. 2006.

[16] Ramezani, M.; Haghifam, M.-R.; Singh, C.; Seifi, H.; Moghaddam, M.P.; , "Determination of Capacity Benefit Margin in Multiarea Power Systems Using Particle Swarm Optimization," Power Systems, IEEE Transactions on , vol.24, no.2, pp.631-641, May 2009

[17] Hagkwen Kim; Singh, C.; , "Reliability Modeling and Simulation in Power Systems With Aging Characteristics," Power Systems, IEEE Transactions on , vol.25, no.1, pp.2128, Feb. 2010

[18] Atwa, Y.M.; El-Saadany, E.F.; Salama, M.M.A.; Seethapathy, R.; Assam, M.; Conti, S.; , "Adequacy Evaluation of Distribution System Including Wind/Solar DG During Different Modes of Operation," Power Systems, IEEE Transactions on , vol.26, no.4, pp.1945-1952, Nov. 2011

[19] Songzhe Zhu; Yi Zhang; Chowdhury, A.A.; , "Capacity credit of wind generation based on minimum resource adequacy procurement," Industry Applications Society Annual Meeting (IAS), 2011 IEEE, vol., no., pp.1-6, 9-13 Oct. 2011

[20] Chao-Shun Chen; Cheng-Ta Tsai; Cheng-Ting Hsu; Hui-Jen Chuang;, "Capacity expansion planning of distribution substations considering PV penetration," Industrial \& Commercial Power Systems Technical Conference (I\&CPS), 2012 IEEE/IAS 48th , vol., no., pp.1-7, 20-24 May 2012 